\title{
EL HUMANISMO DE ANTONIO GAMONEDA EN SUS LÍMITES
}

\section{José Antonio EXPÓSITO HERNÁNDEZ}

I. E. S. Las Musas (Madrid)

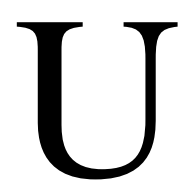

n gran poeta es quien canta siempre con profundidad lo esencial del ser humano. Nunca podrá el verdadero poeta eludir los auténticos enigmas del hombre: el amor, la muerte y la sed por desentrañar el misterio. Cuántas veces hemos visto malograrse o extraviarse por errados rumbos a escritores con grandes cualidades por una excesiva ansia de vanguardismo o, lo que es peor, de superficialidad por hacer concesiones estéticas a los fáciles.

Solo aquellos poetas en los que es posible destacar suficientemente su cardinal humanismo como núcleo de su obra son capaces de atraer la atención de quienes buscan la palabra poética y también la de los que no esperaban hallarla. El poeta auténtico ha de lograrlo a través de una expresión nueva y distinta de quienes le precedieron en el uso del verso. No basta con repetir lo mismo en idénticas formas. La clave consiste en hallar el verbo adecuado, propio de cada época, aquel que acierte a cantar lo eterno del hombre con la expresión depurada de cada tiempo y propia de cada lugar. Así, pues, siguiendo a Walt Whitman, no se puede afirmar que un poeta es superior a otro, ya que cualquiera que llena su época y su lugar a cualquiera iguala. En cuestión de escalas en el arte no se es más ni menos. Se es o no se es, simplemente.

El hondo humanismo de la poesía de Gamoneda nos servirá para mostrar la verdad de estas afirmaciones. ¿En qué consiste ese profundo humanismo?

Algunos creen que quien habla en sus versos de actividades cotidianas propias de cualquier individuo actual son válidas para afirmar una poesía de vocación humana. Lo que realmente indaga en lo sensible es buscar lo sustancial del hombre, aquello que nos hace sentir nuestra verdadera condición de conciencia mortal. Si se pidiese a cualquier lector que ilustrase con algunos versos esta vertiente de Gamoneda, sin duda abrirían al azar por cualquiera de las páginas de Blues castellano y hallarían numerosos y certeros ejemplos de esa faceta del humanismo fácilmente reconocible: la fraternidad, la solidaridad o la sed de justicia. El dolor humano, el sufrimiento en la existencia es lo que poseen en común la mayoría de estos poemas. Blues castellano es un canto de queja y de consolación al mismo tiempo, que se encuadra dentro de la confluencia de dos tradiciones de poesía popular: la castellana y la que trae la novedad de los ritmos negroamericanos del blues. 
Pero, en cambio, nos interesa ahora ahondar en otro aspecto del humanismo, el que alza al poeta hacia otra dimensión más atemporal. No queremos afirmar que esos valores del primer humanismo no sean primordiales, pero será la palabra que se eleve de la humilde vivencia hacia otra más alta realidad la que nos ofrezca la compleja dimensión del hombre. Nos referimos a esa palabra del poeta que trasciende lo que percibe, la del que mirando las cosas sencillas no puede dejar de ver otra oculta realidad, la de quien siente el terrible abismo de la existencia y es capaz de crear belleza con tan delicados y sutiles mimbres.

¿En qué consiste ese humanismo de Gamoneda, si no se quiere destacar, como sería fácilmente reconocible, esa veta citada de su poesía en la que afloran escenas llenas de la belleza de la vida sencilla, aunque trascendidas por la palabra poética?

Para quien esto escribe fue una honda alegría hallar el alto humanismo de Gamoneda precisamente en sus límites. En los límites de su verso con la nada, en la expresión serena, armoniosa del poeta ante la encrucijada más difícil: ante el fin de la existencia. Ahí, en esa linde de la vida con la muerte alcanza la poesía de Gamoneda su voz verdadera, que se ha ido gestando a lo largo de cincuenta años de creación y que en el Libro del frío revela su más honda dimensión humana. Un poeta sin fe en un más allá, ni creencia en ninguna salvación posible se siente desnudo de vida y se sienta a contemplar la muerte, tal y como leemos al final de Lápidas: «Siéntate ya a contemplar la muerte». La poesía que nace desde esa perspectiva resulta inquietante. Gamoneda ha dejado de lado cualquier lastre histórico o biográfico, como sucedía en Descripción de la mentira o en Lápidas. Prescinde de las circunstancias espaciales o temporales, para llenarse de intensidad lírica, a través de un yo poético situado tanto física como psíquicamente, frente al territorio incierto del final. Un sujeto poético que encarna en su reflexión la incertidumbre de cualquier persona ante el fin de su vida. Y ese «yo», a fuerza de ser profundamente subjetivo, es todos los hombres, de ahí su alcance y el vuelo que vibra fuertemente humano en estos versos.

Es una poesía que se despoja de sucesos accesorios para cantar exclusivamente la soledad de haber llegado a una edad desde la que se vislumbra la certeza de la muerte. En la soledad no se encuentra más que lo que lleva uno a ella, y lo que Gamoneda lleva permanentemente consigo a lo largo de tantos años de escritura poética no es otra cosa más que su propio miedo a la muerte.

La poesía de Antonio Gamoneda está llena de vida, hecha con materiales de su propia existencia. Jamás es una poesía fría, jamás se sacrifica la verdad ante la belleza. Como tampoco se limita a ser una redacción de hechos relacionados directa o indirectamente con el autor. Su obra no es literatura, sino poesía sentida y sincera, elaborada y construida que indaga siempre acerca de la vida y sus límites. Sobre esta idea es necesario aclarar que para Gamoneda hay una enorme distancia entre literatura y poesía. La literatura, según nuestro autor, imita la realidad, es una ficción; en cambio, la poesía no es una ficción, porque no es una escritura referente a la realidad, es autorreferente, lleva en sí misma la realidad. La poesía para Gamoneda «no es escritura sobre la vida, sino que es una emanación de la 
vida como la respiración o el amor» ${ }^{1}$. Es notable la coincidencia de lo expuesto por Gamoneda con la misma distinción que creía y defendía Juan Ramón Jiménez entre literatura y poesía:

La literatura es traducción, la poesía original. Si la poesía es para los sentidos profundos, la literatura es para los superficiales; si la poesía es instintiva y por lo tanto tersa, fácil como la flor o el fruto, si es de una pieza, la literatura, dominada como está, obsesionada por lo esterior que tiene que incorporarse, será trabajada, premiosa, yuxtapuesta, barroca. ${ }^{2}$

Ambos poetas coinciden en la idea de que la poesía es algo natural, frente a la literatura que es artificial. En este punto es preciso establecer la distinción entre ficción y autobiografía dentro de la poesía de nuestro autor. Antonio Gamoneda no habla de un mundo interior de manera exclusiva, no es la suya una poesía vuelta sobre su propio ser en la que prime la introspección reducida a la individualidad íntima, sino que se trata de una vida vivida y después interiorizada, que luego será el verdadero germen poético. Solo entonces se alcanza ya una auténtica significación colectiva o histórica $^{3}$. Tal y como ha sucedido admirablemente con su libro Descripción de la mentira, que ha sido reconocido como una cima indiscutible de la poesía de posguerra al haber sabido expresar con belleza y verdad el fracaso de una generación, de una época y también, en definitiva, de todo un país. Descripción de la mentira es un extenso poema que ejercita la memoria, no desde un pensamiento lógico destemporalizado, sino desde intuiciones del propio existir, expresadas a través del yo poético, que va hacia la muerte. Hay, pues, conciencia de un tiempo ya desaparecido y conciencia también de un ir hacia el final. Por ello, decíamos antes que, según Gamoneda, la poesía existe porque caminamos hacia la muerte.

Surge aquí de lleno el problema de la identidad del sujeto lírico. Este en el caso de Gamoneda responde a la tradición literaria de un desvío figurado con relación al sujeto autobiográfico, es decir, al propio poeta Antonio Gamoneda. De esta manera, se supera la anécdota autobiográfica gracias a esa ficción alegórica del sujeto lírico para abrirse a un significado más universal que libera a este sujeto de la circunstancia espacio-temporal. A pesar de ello, no se trata de un yo entendido como una unidad abstracta, como una forma pura, sino que a través del sujeto lírico en la poesía de Gamoneda aparece una experiencia vivida, el Erlebnis ${ }^{4}$ del que hablan los críticos alemanes, entendida como posibilidad de cualquier otra vida humana, superando así el mero testimonio autobiográfico. Y así, gracias a este valor universal que alcanzan los sentimientos expresados por el sujeto poético, su confesión individual en tantos poemas se transforma en poesía lírica. Y el sujeto lírico es también el sujeto de una enunciación real, de acuerdo con Kate Hamburger ${ }^{5}$.

\footnotetext{
${ }^{1}$ Palabras de Antonio Gamoneda pronunciadas en la conferencia titulada «Sufrimiento y poesía», leída el 22 de febrero de 2001, en la Fundación de Ciencias de la Salud, dentro del ciclo «Con otra mirada».

2 J. R. Jiménez (1961), El trabajo gustoso (Conferencias), 37.

${ }^{3}$ Sobre este asunto escribe Jorge Guillén (1962): «Representando a los grandes líricos de su país y de su tiempo asienta como verdad fundamental Coleridge: "Todos los verdaderos poetas coinciden en un punto: todos escriben desde dentro, gracias a ese principio interior, y no por algo que se origine fuera"», «Lenguaje y poesía», Revista de Occidente, 148.

${ }^{4}$ R. Wellek (1999), «La teoría de los géneros, la lírica y el Erlebnis», VV. AA., Teorías sobre la lírica, 25.

${ }^{5}$ K. Hamburger (1995), La lógica de la literatura, trad. J. L. Arantegui.
} 
Según lo anterior: ¿Cuál es el núcleo, la constante «interiorizada» de Antonio Gamoneda? ¿Cuál es la experiencia vivida, la raíz que alimenta y da sentido a toda su obra poética? El propio Antonio Gamoneda ha afirmado al respecto en una entrevista lo siguiente:

[...] yo soy un hombre que escribe desde el miedo, y el miedo se refiere siempre a algo que va a ocurrir, no es algo que esté sucediendo -a lo que está sucediendo no se le tiene miedo, se huye de ello...-, el miedo es siempre hacia allá...; entonces: yo estoy en la contemplación de la muerte; se trata, por tanto de una proyección hacia el futuro...6

La raíz por lo tanto es el miedo, es la contemplación de la muerte, es el miedo a la muerte. Esta es la constante de la escritura del poeta a lo largo de su vida, y configurará lo que él mismo ha definido como su peculiar «poética de la muerte». Esta conciencia de la muerte, esta perspectiva de la muerte en Antonio Gamoneda, viene unida indisolublemente a la poesía y a la desaparición de su padre, también poeta (Antonio Gamoneda, muerto en 1932), cuando nuestro autor apenas contaba con un año de edad. La poesía y la muerte gravitaron muy pronto sobre Gamoneda. A esto hay que añadir la terrible experiencia de la Guerra Civil para un niño en un barrio de León, «circunstancia cruelmente histórica», como la califica el autor, que le hizo ser testigo desde los balcones de su casa de «cuerdas de prisioneros» hacia la muerte en los depósitos carcelarios de San Marcos ${ }^{7}$.

Como resulta previsible, ya desde sus primeros poemas la muerte está presente de forma necesaria y consustancial con sus versos. No solo como reflejo de las circunstancias históricas vividas, sino también por el peculiar carácter del autor. Algo de ello se intuye en el primer poema que publicó Gamoneda en la revista alicantina Verbo, en el año 1949, titulado precisamente así, «Los muertos» ${ }^{8}$. Curiosamente, Gamoneda no ha destacado este hecho, pero sí declara en una entrevista lo siguiente:

En el año 51 yo hablo de la muerte ya. Yo tenía veinte años. Y hablo de mi juventud, y de mis deseos, y de mis ilusiones eróticas..., de todo lo que zoológica y existencialmente caracteriza al deseo, y en términos hasta groseros. Pero la muerte no es una idea. Yo digo en el año 51: "el sabor a muerto en mi lengua". Estoy experimentando la muerte. Y vivo de manera distinta, pero vivo en camino, incluso poéticamente, hacia la muerte. Por eso, la poesía es el relato de cómo se va hacia la muerte. ${ }^{9}$

Para los existencialistas la muerte reside en el interior del ser humano como peculiaridad propia definitoria de su existencia. La muerte no es sino la última posibilidad del hombre, es la posibilidad de la imposibilidad de su existencia. Heidegger lo expresa así: «La muerte es la posibilidad de la absoluta imposibilidad del "ser ahí"»»".

Ese ir hacia la muerte es también y al mismo tiempo reflexión de todo aquello que en ese tránsito se va perdiendo, de ahí que el poeta afirme en Descripción de la mentira lo siguiente: «Todos mis actos en el espejo de la muerte» ${ }^{11}$. En este certero verso Gamoneda une de forma admirable el momento

\footnotetext{
${ }^{6}$ F. Martínez García (1991), Gamoneda, una poética temporalizada en el espacio leonés, 32

${ }^{7}$ Esta y otras escenas podemos leer transformadas en sustancia poética en el apartado correspondiente a Lápidas, A. Gamoneda (1987), Edad, 321.

8 A. Gamoneda (1949), «Los muertos», Verbo. Cuadernos literarios, 5.

${ }^{9}$ F. Martínez, Gamoneda, una poética temporalizada en el espacio leonés, op. cit., 43.

${ }^{10}$ M. Heidegger (1977), El ser y el tiempo, 273.

${ }^{11}$ A. Gamoneda, Edad, op. cit., 285.
} 
presente a través de la contemplación de un pasado: «Mis actos en el espejo», y el futuro irremediable: «La muerte». Todo ello, para mostrar que cada una de estas determinaciones del tiempo no tiene significado de forma aislada, si no es respecto a la otra. Esto es, respecto a un «fuera de sí», como señala Heidegger. Antonio Gamoneda reflexiona sobre este verso y muestra la correlación entre el miedo y la muerte: «iEn el espejo de la muerte! Pues bien, mi tránsito hacia el espejo de la muerte es el miedo..., y el miedo se proyecta al futuro» ${ }^{12}$.

En libros más recientes esta actitud estética, esta reflexión ante la muerte se renueva y acrecienta. Así en Lápidas, libro ya de madurez, se dice: «Siéntate ya a contemplar la muerte» ${ }^{13}$, o también en el Libro del frío: «He atravesado las cortinas blancas: ya sólo hay luz dentro de mis ojos» ${ }^{14}$. La luz como umbral de la muerte será un símbolo muy frecuente en la poesía de Gamoneda, tal y como se analizará más adelante.

El presente, que es la vida, es miedo del futuro donde siempre se hallará la muerte. Mientras el poeta va dejando un discurso vital y poético, incoherente a veces, y otras, las más, incomprensible: «Este relato incomprensible es lo que queda de nosotros» ${ }^{15}$. Sobre este verso de Descripción de la mentira comenta el propio autor a Francisco Martínez:

Fíjate bien, estoy hablando de un presente de este relato: "lo que queda de nosotros"; pero estoy aludiendo también a un tiempo pasado. Y hay otro sitio en el que digo lo es este relato: ...los poemas, en cuanto actos humanos, estarán colocados en el "medio", que es el presente, desde el que se contempla el futuro en la perspectiva del "final", al que el hombre se va acercando irremediablemente... ${ }^{16}$

La idea de que el hombre es un ser hecho para la muerte y de que esta ya está presente desde el nacimiento, sitúa por otro lado a Antonio Gamoneda dentro de nuestra más clara tradición poética: desde Jorge Manrique y la poesía del Barroco hasta Antonio Machado. Y es a través de la influencia de este último como llega el pensamiento existencialista de Heidegger hasta nuestro poeta. Segundo Serrano Poncela dice a propósito de la poesía de Antonio Machado: «La resignada amargura que subterráneamente corre junto a la melodía de cada poema responde a esta impregnación de substancia mortis, a esa concepción de la vida del hombre como ser para la muerte» ${ }^{17}$. Y es aquí, en ese reconocer la posibilidad de la muerte, en el asumirla donde el hombre encuentra su ser auténtico. Aquí es donde coincide Gamoneda con Antonio Machado y Heidegger. Para este último, vivir para la muerte significa comprender la imposibilidad de la existencia en cuanto tal. «La muerte -dice Heidegger- como posibilidad, no da al 'ser ahí' nada 'que realizar', ni nada que como real pudiera ser él mismo» ${ }^{18}$. En la angustia, el hombre se siente en presencia de la nada y el acto de la trascendencia, de ir más allá de la realidad existente, es una imposibilidad radical, es una nada aniquiladora. Todo este poso filosófico se

\footnotetext{
${ }^{12}$ F. Martínez, Gamoneda, una poética temporalizada en el espacio leonés, op. cit.,33.

${ }^{13}$ A. Gamoneda, Edad, op. cit., 353.

14 A. Gamoneda (1992), Libro del frío, 151. Sobre el simbolismo de la luz al final del camino en la obra de Antonio Gamoneda, véase el artículo de M. Casado (2000), «PPlacer sin esperanza?», Revista de Libros de la Fundación Caja Madrid, 35-36.

${ }^{15}$ A. Gamoneda, Edad, op. cit., 285.

${ }^{16} \mathrm{~F}$. Martínez, Gamoneda, una poética temporalizada en el espacio leonés, op. cit., 34.

${ }^{17}$ S. Serrano Poncela (1954), Antonio Machado, su mundo y su obra, 132.

${ }^{18}$ M. Heidegger, El ser y el tiempo, op. cit., 286.
} 
halla en las declaraciones de nuestro poeta: «El sabor a muerto en mi lengua, el espejo de la muerte, estar químicamente desesperado... son cosas que se pueden rastrear en mi poesía. Yo soy un animal que se siente morir desde que nace. Se da la circunstancia de que ese animal escribe» ${ }^{19}$.

Y el poeta Antonio Gamoneda escribe precisamente el siguiente verso con el que se cierra su libro más conocido, Descripción de la mentira: «QQué hora es ésta, qué yerba crece en nuestra juventud? $\gg^{20}$. Y dice a propósito de dicho final:

¿Qué yerba crece? ¡La de la muerte, coño! Aunque también pudiera ser una yerba sin nombre. ¿Qué hora es ésta si no logro agarrarla? Sí, exactamente, como si despertara de un sueño. Ahí tengo la memoria, ahí tengo mi miedo, ahí tengo mis dos vectores. ¿Qué hora es ésta, qué pasa aquí, en qué momento estoy en relación con la muerte?, este relato incomprensible ¿a qué presente me ha llevado? No tengo, no lo veo, o si lo veo no lo reconozco..., más bien no lo reconozco... Si antes se ha dicho «este relato incomprensible», se trata de algo que ya ha sucedido, porque no se relata el futuro. Incomprensible es lo que queda de nosotros. El "queda" es el presente. "Este relato incomprensible"... no es más que, eso, incomprensible. Los presentes son: "es incomprensible" -es incomprensible ahora- ${ }^{21}$

Ahora bien, aunque la poesía de Gamoneda está en este sentido en clara sintonía con lo que escribieron algunos otros poetas españoles de la década de los cuarenta o de los primeros años cincuenta, nuestro autor no cae en los desesperanzados gritos existenciales de aquellos y así dice en el poema «Sublevación»: «Advertid que tan sólo / a los perros conviene / crecimiento de alarido» ${ }^{22}$.

Entre tantos poetas que expresaron ese desgarro existencial, sobresalen dos por ser estos los que más honda huella dejaron en nuestro autor. Se trata de Blas de Otero y de Dámaso Alonso. El primero expresaba su miedo a la muerte en términos muy existencialistas: «vértigo», «abismo», «sombra», «cuchillo», etc., incluso declara su deseo de no haber nacido en el poema «Tierra»: «Caerme, revertir, no haber nacido / humanamente nunca en ningún vientre». También Dámaso Alonso en Hijos de la ira, insiste en la angustia del hombre ante la muerte a través de imágenes irracionalistas. Por lo tanto, Gamoneda en estos poemas iniciales se halla inmerso dentro de una tradición y de una corriente existencialista, no privativa de la poesía española de posguerra, sino también de la literatura y el pensamiento europeo de la época. La lectura de Orfeo negro, poesía y revolución, de Jean-Paul Sartre, influyó decisivamente en la manera de escribir poesía de Gamoneda, tal como reconoció el poeta.

Pero, ¿esta consideración de la muerte en la poesía de Gamoneda es siempre la misma? Y si no es así, ¿en qué sentido se transforma el tratamiento de la muerte en su evolución poética? A continuación, se da respuesta detallada a estas cuestiones, pues contribuirán decisivamente después a señalar con mejor criterio las posibles etapas de la escritura del autor.

En los primeros poemas de Gamoneda aparece una consideración de la muerte más general, impersonal, podríamos decir, hasta cierto punto incluso más literaria. No hay todavía una verdadera y meditada concepción individual de esta circunstancia. Por lo tanto, en los primeros títulos como $\mathrm{La}$ tierra y los labios o Sublevación inmóvil la muerte es abordada desde un tratamiento que está en

\footnotetext{
${ }^{19}$ F. Martínez, Gamoneda, una poética temporalizada en el espacio leonés, op. cit., 44.

${ }^{20}$ A. Gamoneda, Edad, op. cit., 285.

${ }^{21}$ F. Martínez, Gamoneda, una poética temporalizada en el espacio leonés, op. cit., 44.

${ }^{22}$ A. Gamoneda, Edad, op. cit., 110.
} 
consonancia con una tradición y unos modelos literarios ya conocidos. En cambio, en los siguientes libros el autor muestra un pensamiento mucho más original y profundo. No se trata de que no sean sentidos estos primeros versos, sino que aún no aflora esa reflexión tan característica de Gamoneda que sí aparece en las siguientes obras. Las realidades cotidianas junto a la queja solidaria de las que se ocupan los blues de su libro Blues castellano: el trabajo, la casa, la familia, etc., o también la confianza que produce el amor en Exentos I alejan la muerte de la poesía de Gamoneda momentáneamente.

En Lápidas la memoria evoca la edad del pasado de forma fragmentaria. Se aborda la muerte de los otros, de los que ya fueron. Los referentes son más claros que en Descripción de la mentira: el terrible fracaso que provoca la guerra, la muerte de una época y en definitiva de todo un país. Tras ello Dios no es más que un silencio tenaz, es un vacío, una desnudez que no existe, un hueco cierto para el hombre. Frente al discurso continuo que se ofrecía en Descripción de la mentira encauzado a través de unos largos versículos, ahora se busca decididamente una forma estrófica singular. No se trata de ninguna estrofa clásica, sino que el poeta recoge retazos, estampas aisladas de la memoria en esos fragmentos poéticos. De ahí que la imagen utilizada en el propio título del libro Lápidas, sirva para expresar metafóricamente tanto la forma de los poemas, así como también el sentido de los mismos. El pasado ha sido fijado ya por una memoria lírica que no histórica, en esas «lápidas». Y al sujeto poético ya no le queda sino reflexionar sobre lo venidero, el desenlace vital, con una estética de luz fundada en la soledad y el silencio que huye conscientemente de lo funesto y del desgarro expresivo. Lo cual da como resultado una poesía profundamente nueva y al mismo tiempo plenamente humana.

No se trata de una muerte abstracta o ajena, sino de la propia muerte, la que se espera desde la edad aún de la existencia, aunque se perciba con claridad ese desenlace: «Soy el que comienza a no existir» ${ }^{23}$. Será en el Libro del frío donde desde la vejez el poeta desarrolle y culmine ese interesante asomarse a la luz del final.

No será hasta la aparición de Descripción de la mentira, cuando el autor inicie esa peculiar visión de la muerte. Se trata de una reflexión que se aventura sobre la propia muerte, a la que se empieza ya a mirar cara a cara. Es decir el sujeto poético expresa la situación de haber vivido lo suficiente para reconocer que ha llegado a las proximidades del final de la vida, a la frontera de esta con la muerte. El yo lírico considera ahora la muerte sobre todo como un fin exclusivamente individual, y se refiere fundamentalmente a su propia muerte personal. Y esto provoca una singular poesía que se sitúa ahora en los límites, sin querer nunca ir más allá, sin buscar la trascendencia. La palabra muerte es eludida frecuentemente mediante símbolos de actitudes y procesos ante ese final, pues en los poemas se prefiere hablar de lindes, umbrales, límites y fronteras, territorio del final, territorio blanco, la nieve o la luz. En estos contornos difusos y escasos quiere situarse la poesía de Gamoneda en sus últimos libros: Lápidas, Libro del frío o Arden las pérdidas. En todos ellos leemos quizá por haber sido ya plenamente interiorizada, una reflexión poética desolada del autor sobre la muerte y sin duda una de las más sorprendentes y conmovedoras de la última poesía española de posguerra.

${ }^{23}$ Ibid., 362. 
Se llega al Libro del frío desde aquel inicial conflicto existencial de los primeros poemas, pero con una sustancial diferencia en la profundidad con que se aborda ahora el tratamiento de la muerte. Ya se ha logrado una hondura de pensamiento y una riqueza de matices que son fruto de una dilatada y variada experiencia vital. Se juzga la muerte como un vacío que intensifica la conciencia del sujeto poético. El resultado ha sido una obra que culmina brillantemente un largo proceso artístico. En el Libro del frío el yo poético reflexiona en torno a los límites últimos de la vida, la frontera de la edad con la muerte. Se ahonda en un territorio confuso de los límites, de la vejez con una gran precisión de imágenes que enriquecen con nuevos matices la citada idea.

No hay en la poesía de Gamoneda una búsqueda de continuidad en el más allá. Gamoneda no cree en ninguna salvación posible. La conciencia del sujeto poético revela en hermosa intimidad lírica cómo ha asumido encontrarse ante los límites de la vida. La imposibilidad de mostrar algo inaccesible para los sentidos como es la experiencia de la muerte provoca que el espacio de la poesía sea una frontera luminosa entre la propia vida y la inexistencia. Toda la fuerza de esta representación poética reposa no ya en el trazo perfilado de la muerte, sino en quedarse tan solo con la luz que asociamos al sentimiento. Por esta razón se ha destacado esta circunstancia como un espacio interior de la conciencia.

Si Heidegger afirmaba que lo que existe lo fundan los poetas, Gamoneda es un claro ejemplo de ello, ya que sus versos están ensanchando la existencia, ampliando esa leve linde entre la vida y la muerte, dilatando esa delgada línea de un paisaje confuso entre la mirada y la nada. En definitiva, fundar un nuevo espacio que luego transitarán las conciencias de los demás, pero que antes no existía. Este es, a nuestro juicio, el profundo humanismo de Gamoneda. La hermosa hondura del poeta verdadero que agranda con sus versos nuestra verdadera dimensión humana.

El Libro del frío gira en torno al haz isotópico que configura la muerte, y más concretamente alrededor del ya citado miedo a la muerte, del miedo cierto por la cercanía de lo invisible. El poeta se pregunta: «¿Qué hago yo delante del abismo?». Se trata de un espacio límite que es necesario vigilar, pero, sobre todo, existe la conciencia lúcida de haber llegado hasta allí, después de un transcurso vital. Surge entonces la lucha con la palabra para expresar ese hallazgo. Y es en ese momento cuando el yo recurre a símbolos para expresar líricamente ese territorio del confín.

No obstante, Gamoneda ha sabido aligerar los poemas de dramatismo efectista, de tenebrismo. Es un sentimiento muy personal en el que el lector encuentra algo que no le es ajeno y se reconoce en esos versos. Destaca especialmente una visión profundamente subjetiva de ese límite de la vida con el misterio, expresada a través del color blanco y sus diversas variantes. Es una inserción afortunada en un tema largamente tratado a lo largo de los siglos. Ese es, a nuestro parecer, el verdadero valor de este libro: haber rechazado el camino más transitado por otros muchos poetas, para hablar del color del miedo y de la muerte con un subjetivismo extremo, lo cual da como resultado una poesía de gran originalidad y personalísima dentro de la poesía española de posguerra.

Se crea en estos poemas una atmósfera plena de luminosidad que es la consecuencia de la desaparición del resto de los colores al abolir el mundo de los objetos reales. Ha quedado solo la luz, 
el color blanco que es unidad, es el color en el que se reúne la diversidad de los demás colores. Tan solo brilla la desnuda claridad del límite.

Los lexemas «luz»y «oscuro» expresan a través de un complejo tejido de oposiciones, una red textual que queda definida como la experiencia poética de hallarse ante los límites de la vida, en el extremo de lo inmanente. Y en esta linde de la existencia el poeta muestra cómo se anulan y confunden las dicotomías. El «territorio blanco» es ahora el símbolo nuevo que habla de forma certera y original de un espacio interior de la conciencia que se sitúa ya ante la inmediatez de su propio final.

Tanto el Libro del frío como Arden las pérdidas son, sin duda, obras en las que sobresale una compleja lírica de límites. No solo por el intento de expresar la difícil situación de un sujeto poético orillado ante el final de la vida, sino porque también en estos poemas se buscan los límites formales del género poético.

Asociada a esta cosmovisión del final, a esta poesía de los límites encontramos un verso que desde los primeros libros se va liberando de toda atadura formal para situarse en los títulos más recientes, también en otros límites, los que separan la prosa y el verso. Hay en la poesía de Gamoneda una progresión continuada en lo que respecta a la forma del verso. En los primeros libros se utilizan moldes clásicos, como el soneto o el alejandrino. Después el poeta se inclina por el endecasílabo blanco, luego la novedad la constituyen los blues, cuyo ritmo repetitivo se emplea por primera vez en la poesía española. Finalmente en las últimas obras se alcanza una gran libertad formal que prescinde de la disposición versal, de la rima y también de la estrofa. Se busca la libertad en la disposición gráfica: el versículo mayor sirve de cauce al monólogo interior y los poemas en prosa configuran un verdadero relato lírico. Hay en Gamoneda un progresivo alejamiento de preceptivas además del rechazo de los límites que impone la tradicional distinción entre prosa y verso.

Se trata de una poesía que evoluciona desde unos planteamientos marcadamente literarios ante la muerte y unos moldes poéticos tradicionales, hacia una meditación sobre los límites últimos de la vida expresada a su vez desde los límites formales del género poético ${ }^{24}$.

Ahora bien, la poesía de Gamoneda llega en estos últimos libros a una difícil situación de continuidad o avance, ya que situada en los límites finales de la existencia apenas encuentra otra salida coherente en esos confusos y exiguos contornos que el silencio último. Sin embargo con la publicación en 2004 de Cecilia, último libro de Gamoneda hasta hoy, su poesía vuelve a mirar a través de una hermosa niña, su nieta, de nuevo hacia la vida. Es un renacer de la vida a más vida. El invierno no sale a la muerte, sino a la primavera. Se resuelve así, quizá tan solo de forma momentánea pero sin duda esperanzadora y sin que se haya dado un paso en falso en una coherente evolución poética, la compleja encrucijada en la que se hallaba el poeta.

Gamoneda ha sido plenamente consciente de haber cumplido con el contenido de su conocido verso de Lápidas: «Siéntate ya a contemplar la muerte». Y por ello ve ahora con alegría en los versos

\footnotetext{
${ }^{24}$ J. A. Expósito Hernández (2003), La obra poética de Antonio Gamoneda.
} 
de Cecilia, cómo la vida se sucede a sí misma y cómo de tanto mirar la muerte al fin ha soñado, no con una salvación en la que evidentemente no cree, sino con una hermosa luz hecha de nuevo más vida.

\section{Referencias bibliográficas}

CASADO, Miguel, «¿Placer sin esperanza?», Revista de Libros de la Fundación Caja Madrid, núm. 47 (noviembre de 2000).

EXPÓSITO HERnÁNDEZ, José Antonio, La obra poética de Antonio Gamoneda, Madrid, Universidad Complutense de Madrid, 2003. Véase en: http://eprints.ucm.es/tesis/fll/ucm-t26672.pdf.

GamonedA, Antonio, «Los muertos», Verbo. Cuadernos literarios, núm. 17 (octubre-diciembre de 1949).

— Edad, Madrid, Cátedra, 1987.

—, Libro del frío, Madrid, Siruela, 1992.

GuILLÉN, Jorge, «Lenguaje y poesía», Revista de Occidente (1962).

Hamburger, Käte, La lógica de la literatura, trad. J. L. Arantegui, Madrid, Visor, 1995.

HeIDEGGER, Martin, El ser y el tiempo, México, Fondo de Cultura Económica, 1977.

JiMÉNEZ, Juan Ramón, El trabajo gustoso (Conferencias), Madrid y México, Aguilar, 1961.

MARtínez García, Francisco, Gamoneda, una poética temporalizada en el espacio leonés, León, Universidad de León, 1991.

Serrano Poncela, Segundo, Antonio Machado, su mundo y su obra, Buenos Aires, Losada, 1954. WELLEK, René, «La teoría de los géneros, la lírica y el Erlebnis», VV. AA., Teorías sobre la lírica, Madrid, Arco/Libros, 1999. 